\title{
Инициация побегообразования в культуре апикальных меристем у сортов винограда в условиях Красноярского края
}

\section{Initiation of sprout formation in the culture of apical meristem in grape varieties in the conditions of Krasnoyarsk Krai}

\author{
Соболев В. И., Носкова Н. Е. \\ Sobolev V. I., Noskova N. E. \\ Красноярский ГАУ «Институт агроэкологических технологий», г. Красноярск, Россия. \\ E-mails: kostatdot@gmail.com;noscova62@mail.ru
}

Krasnoyarsk State Agrarian University «Institute of Agri-Environmental Technology», Krasnoyarsk, Russia

\begin{abstract}
Peфepam. Работа выполнялась в лаборатории биотехнологии сельскохозяйственных и лесных культур ФГБОУ ВО Красноярского ГАУ. В опыте по размножению винограда в культуре in vitro были использованы сорта 'БЧЗ' и 'Алёшенькин'. Цель работы - исследовать особенности размножения винограда и пути морфогенеза в культуре апикальных меристем. Выявлено, что сорт 'БЧЗ' проявляет наибольшую интенсивность побегообразования, у сорта 'Алёшенькин' отмечено незначительное отставание. У сорта 'Алёшенькин' отмечено наиболее частое образование на одном черенке из пазухи листа двух и более побегов. Были выявлены различные морфологические образования и отклонения от нормы.
\end{abstract}

Ключевые слова. Виноград, микроклональное размножение, метод апикальных меристем, морфогенез, in vitro.

Summary. The work was performed in the laboratory of biotechnology of agricultural and forest crops of the FSBEI HE Krasnoyarsk State Agrarian University. In the experiment on the propagation of grapes in vitro, the varieties ' BChZ' and 'Aleshenkin' have been used. The aim of the work is to investigate the reproduction characteristics of grapes and the paths of morphogenesis in the culture of apical meristem. It was revealed that the variety 'BChZ' shows the greatest intensity of shoot formation, the variety 'Aleshenkin' has a slight lag. 'Aleshenkin' variety has the most frequent formation of two and more shoots on a single stalk from the bosom. Various morphological formations and abnormalities were identified.

Key words. Grapes, in vitro, microclonal reproduction, method of apical meristem, morphogenesis.

\section{Введение}

Виноградарство - это одна из значимых отраслей садоводства и при правильной постановке дела может стать самой экономически эффективной (Медведева и др., 2008). Сибирское виноградарство сегодня - это удивительный феномен стихийно сформировавшегося за последнее десятилетия массового культивирования южного растения в северных условиях. Вредителей у винограда в Сибири (Красноярском крае) нет - не позволяют суровые климатические условия (Курдюмов, 2006). Однако, привозные сорта могут оказаться зараженными карантинными патогенами. В Красноярском крае исследования по размножению винограда в культуре in vitro начались в 2016 г. в лаборатории биотехнологии сельскохозяйственных и лесных культур ФГБОУ ВО Красноярского государственного аграрного университета, первоначально как отклик на потребность личных садоводческих хозяйств, занимающихся разведением винограда. Следует отметить, что в последние два года в крае формируется спрос на безвирусный посадочный материал сельскохозяйственных культур, поэтому актуально исследовать особенности размножения винограда и пути морфогенеза в культуре апикальных меристем.

\section{Материал и методика исследований}

Объекты исследования - сорта 'БЧЗ' и 'Алёшенькин'. В качестве эксплантов послужили фрагменты апикальных меристем, несущие 1-2 примордия листьев с боковыми почками. Составы культу- 
ральных сред на каждом этапе размножения готовили в соответствии с рекомендациями Н. И. Медведевой (Медведева и др., 2010).

Выделение из почек и введение в культуру апикальных меристем проводилось в стерильных условиях ламинарного бокса. В ходе работы было успешно выделено 9 апикальных меристем винограда сорта 'БЧЗ' и 32 апикальных меристемы винограда сорта 'Алёшенькин', которые были инокулированы на среду MS 1, с пониженным содержанием азота. Через 1,5-2 нед. стало очевидно, что 4 экспланта сорта 'БЧЗ' и 13 эксплантов сорта 'Алёшенькин' откликнулись на условия культивирования: в течении четырёх недель сформировали побеги-регенеранты сортов 'БЧЗ', которые достигали 29-36 мм в длину и несли по 5-7 узлов, и 'Алёшенькин', которые достигали 4-12,5 мм в длину и несли по 1-3 узла. Приживаемость составила 44,4 \% у сорта 'БЧЗ' и 40,6 \% у сорта 'Алёшенькин'. Следы заражения отмечены только у сорта 'Алёшенькин' - 6 \%. Таким образом, в культуре апикальных меристем была проведена выгонка стерильных побегов. Полученые в культуре апикальных меристем регенеранты винограда сортов 'БЧЗ' и 'Алёшенькин' в дальнейшем разделяли на микрочеренки и помещали на свежие среды с составом для микроразмножения.

В ходе исследований сравнивались показатели роста и развития микрочеренков двух сортов: динамика побегообразования (рис. 1), а также среднее количество междоузлий, заложившихся на вновь формирующемся побеге. Соотношение количества побегов, сформированных к концу наблюдений, и количества эксплантов использованных в эксперименте отражено на рисунке 2.

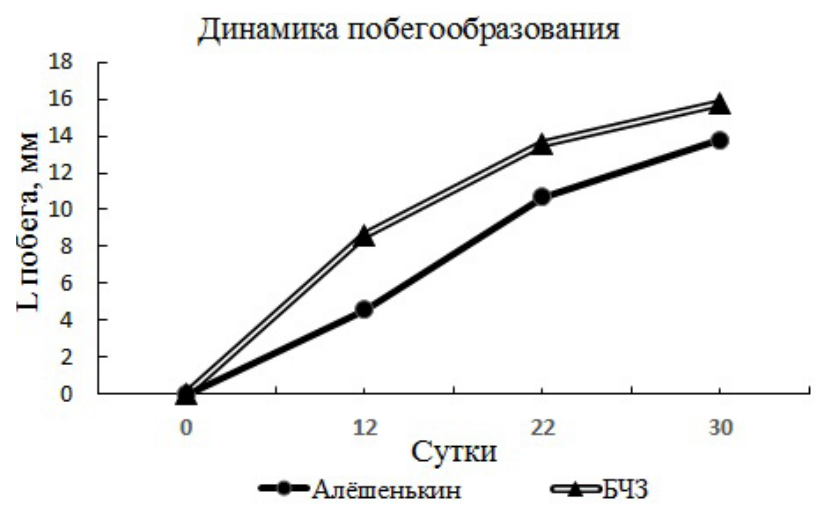

Рис. 1. Динамика побегообразования.

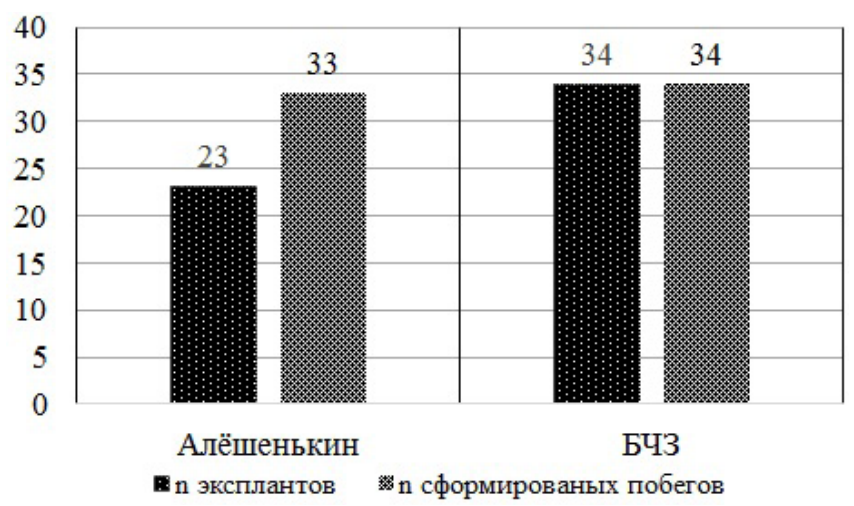

Рис. 2. Количества побегов сформированных к концу наблюдений.

\section{Результаты исследований}

В первые 12 суток наибольшая скорость роста побегов наблюдалась у сорта 'БЧЗ', средняя длина побегов при этом составляла 8,7 мм, у сорта 'Алёшенькин' интенсивность побегообразования была ниже - средняя длина побегов 4,6 мм. С 12 по 30 сутки отмечалось постепенное выравнивание интенсивность роста побегов, отставание сорта 'Алёшенькин' стало менее значительно. К концу наблюдений средняя длина побегов составила: 15,8 мм - у сорта 'БЧЗ' и 13,8 мм - 'Алёшенькин'. В среднем побеги сорта 'БЧЗ' несли 4 междоузлия, сорта 'Алёшенькин' - 3 междоузлия.

У сорта 'БЧЗ' на одном черенке из пазухи листа в 82,4 \% случаев формировался один побег, у сорта 'Алёшенькин' - в 55,6 \% случаев. В остальных случаях отмечено развитие из одного узла 2 и более побегов.

При длительной культивации в световой комнате у побегов отмечено появление жёлто-белого (кремоватого) наплыва - каллуса, от которого могут появиться корни (рис. 3). Частота встречаемости каллусных образований составила у сорта 'БЧЗ' 62,8 \%, 'Алёшенькин' - 100 \%.

В результате многократной культивации сорта 'БЧЗ', у побегов зафиксированы морфологические нарушения: появление каллуса на листе (рис. 4А), витрификация (рис. 4Б), утолщения и срастания побегов (рис. 4B). 


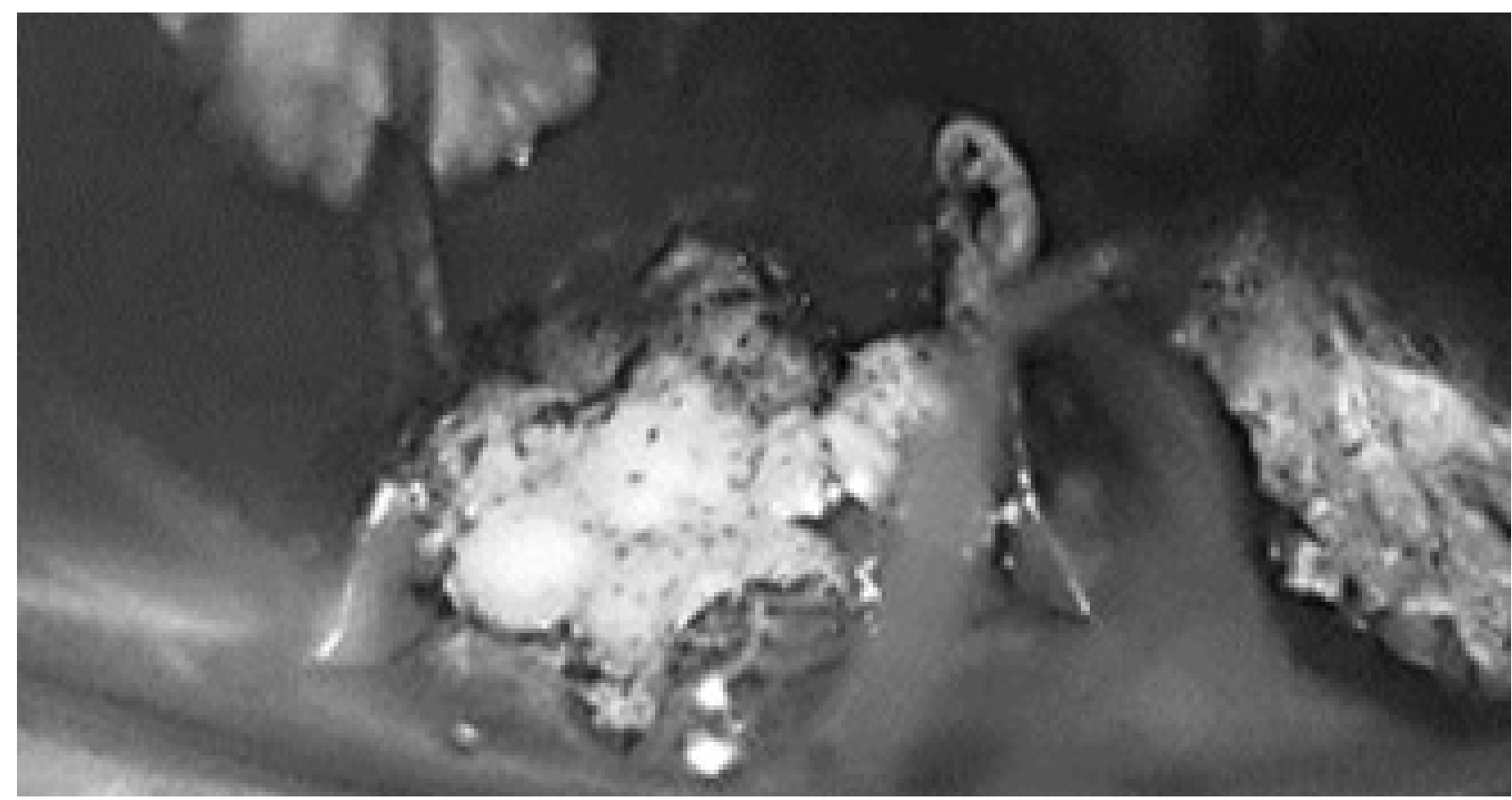

Рис. 3. Каллус винограда (фото автора).
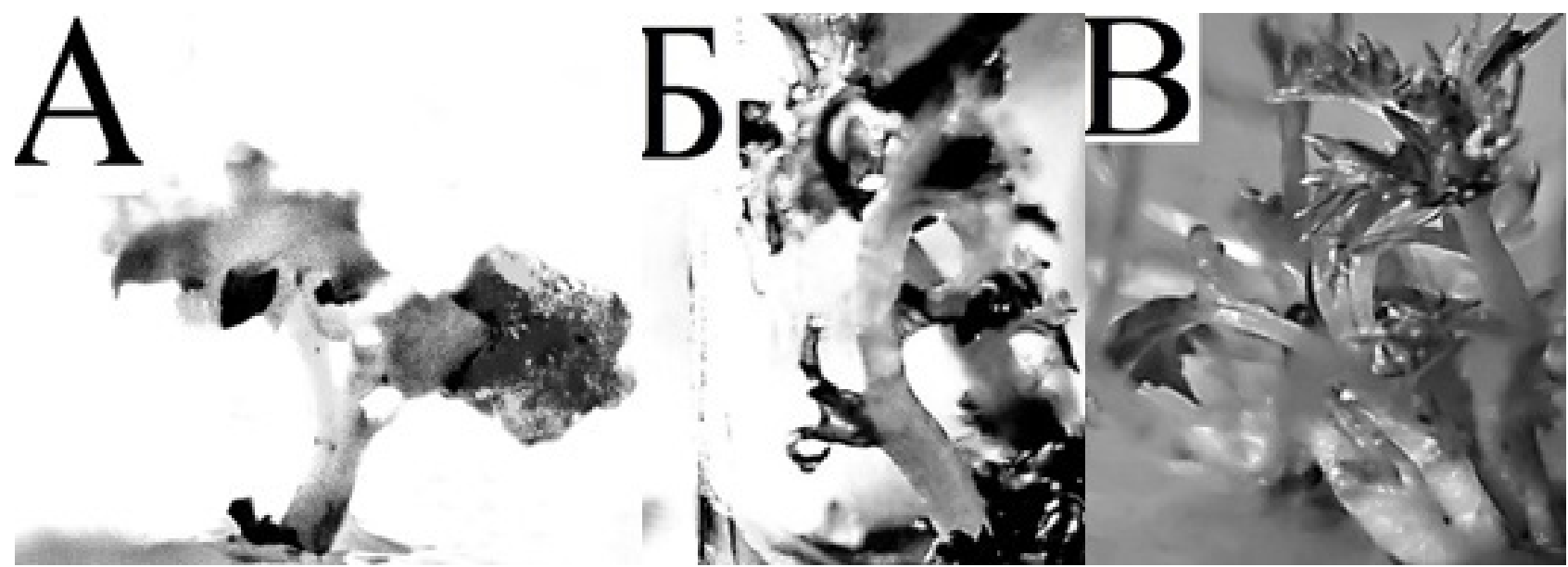

Рис. 4. Морфологические нарушения (фото автора). Условные обозначения: А) Каллус на листе винограда; Б) Витрификация; В) Срастания побегов.

\section{Заключение}

Таким образом, за время наблюдений было выявлено, что сорт 'БЧЗ' проявляет наибольшую интенсивность побегообразования, однако к концу наблюдений отставание в интенсивности побегообразования у сорта 'Алёшенькин' было незначительным. У сорта 'Алёшенькин' отмечено наиболее частое образование на одном черенке из пазухи листа более одного побега. Были выявлены различные морфологические образования и отклонения от нормы.

\section{ЛИТЕРАТУРА}

Курдюмов Н. И. Умный виноградник для себя. - Ростов-на-Дону: Издательский дом «Владис», 2006. - 160 с.

Медведева Н. И., Поливара Н. В., Трошин Л. П. Особенности микроклонального размножения интродуцентов и клонов винограда // Научный журнал КубГАУ, 2008. - № 40(6). - 18 с.

Медведева Н. И., Поливара Н. В., Трошин Л. П. Методические рекомендации по микроклональному размножению винограда in vitro // Научный журнал КубГАУ, 2010. - № 62 (08). - 18 с. 